\title{
An experimental and numerical investigation on the use of phase change materials in building elements: The case of a flat roof in Istanbul
}

\author{
Ayça Tokuç ${ }^{\mathrm{a}, *}$, Tahsin Başaran ${ }^{\mathrm{b}}, \mathrm{S}$. Cengiz Yesügey ${ }^{\mathrm{a}}$ \\ a Department of Architecture, Dokuz Eylül University, DEÜ Tinaztepe Campus, 35160, Buca/İzmir, Turkey \\ b Department of Architecture, İzmir Institute of Technology, IYTE Gülbahçe Campus, 35430, Urla/İzmir, Turkey
}

\section{A R T I C L E I N F O}

\section{Article history:}

Received 10 December 2014

Received in revised form 1 April 2015

Accepted 12 April 2015

Available online 14 May 2015

\section{Keywords:}

Phase change material (PCM)

Computer fluid dynamics (CFD)

Flat roof

\begin{abstract}
A B S T R A C T
This paper reports on the experimental and numerical analysis of a building element-a flat roof-that incorporates phase change material (PCM) as a layer. First, a planar model of the building element of $50 \mathrm{~cm}$ by $50 \mathrm{~cm}$ surface area was constructed in laboratory conditions to be used in the experimental work. During the experiment, changes in the thermal balance were investigated by temperature and volumetric flow rate measurements, as well as observation of the phase change interface. Next, the experimental measurements were used to validate a numerical computer fluid dynamics (CFD) model for simulation purposes. The model is one-dimensional and is based on the first law of thermodynamics. Finally, a time-dependent simulation for summer conditions was performed using the climatic data of İstanbul. The thickness of the PCM inside the roof element was investigated accordingly. The simulation data showed the solid/liquid phase of PCM over time. Monthly graphs were drawn for ease of comparison of the use of PCM with thicknesses varying between 1 and $5 \mathrm{~cm}$. Consequently, a PCM thickness of $2 \mathrm{~cm}$ was found to be suitable for use in flat roofs in Istanbul.
\end{abstract}

(C) 2015 Elsevier B.V. All rights reserved.

\section{Introduction}

The use of solar energy as a renewable energy source is becoming increasingly important as a sustainable alternative against traditional methods of heating and cooling buildings. The building components used in construction play an important role in directing and utilising the received energy in solar systems. However, the intermittent nature of solar energy causes difficulties in practice; thus, during the period that the sun is overhead, the storage of solar energy and utilisation of the stored energy are required. One of the tools used for this purpose is thermal energy storage based on Phase Change Materials (PCMs).

Building elements that contain PCMs have the potential to increase the thermal capacity of the building, consequently reducing the temperature peaks, temperature swings, peak loads, and energy consumption. However, any PCM application in buildings requires a thorough theoretical and experimental examination of the thermal behaviour of the PCM in question. One of the first such

\footnotetext{
* Corresponding author. Tel.: +90 232 3018389; fax: +90 2324532986.

E-mail addresses: ayca.tokuc@deu.edu.tr (A. Tokuç), tahsinbasaran@iyte.edu.tr (T. Başaran), cengiz.yesugey@deu.edu.tr (S.C. Yesügey).
}

studies to classify PCMs in terms of their potential as latent thermal heat storage materials was Abhat [1]. Farid et al. [2] reviewed many of the following PCM studies on the possible applications in which the phase change can be applied as a method of thermal storage. Waqas. and Ud Din [3] provided a comprehensive list of the PCMs currently being used and that can potentially be used for free cooling applications.

Many authors have studied the potential of including thermal energy storage technologies based on PCMs into construction materials and elements. Baetens et al. [4] studied various state-ofthe-art building applications of PCMs. More recently, Soares et al. [5] reviewed passive PCM latent heat thermal energy storage systems. In addition, Pomianowski. et al. [6] reviewed thermal energy storage technologies based on the application of a PCM in buildings. These studies suggested the use of PCMs in many building elements, including roofs, which is the element considered in this study. The use of PCM in roofs has the potential to utilise the incident irradiation on the roof area, reduce the downward heat flow from the roof and mitigate the urban heat island phenomenon, as investigated by Chou et al. [7], Alqallaf and Alawadhi. [8], and Santamouris et al. [9].

Accurate numerical modelling of PCM behaviour in the design phase of buildings would provide essential guidance in optimising 


\begin{tabular}{|c|c|}
\hline \multicolumn{2}{|c|}{ Nomenclature } \\
\hline$c$ & specific heat capacity (kJ/kg K) \\
\hline E & charge or discharge energy $(\mathrm{kJ})$ \\
\hline$h$ & sensible enthalpy \\
\hline$H$ & total enthalpy $(\mathrm{kJ} / \mathrm{kg})$ \\
\hline$h_{\mathrm{o}}$ & $\begin{array}{l}\text { thermal convection coefficient for the outdoors } \\
\left(\mathrm{W} / \mathrm{m}^{2} \mathrm{~K}\right)\end{array}$ \\
\hline$h_{\mathrm{sf}}$ & heat of fusion $(\mathrm{kJ} / \mathrm{kg})$ \\
\hline I & solar irradiation per unit surface area $\left(\mathrm{W} / \mathrm{m}^{2}\right)$ \\
\hline$k$ & thermal conductivity $(\mathrm{W} / \mathrm{m} \mathrm{K})$ \\
\hline$\dot{m}$ & mass flow rate $(\mathrm{kg} / \mathrm{s})$ \\
\hline$p$ & position of the thermocouple ( $\mathrm{mm})$ \\
\hline$t$ & time $(s)$ \\
\hline$T$ & temperature $(\mathrm{K})$ \\
\hline$V$ & volume $\left(\mathrm{m}^{3}\right)$ \\
\hline$\dot{V}$ & volumetric flow rate $\left(\mathrm{m}^{3} / \mathrm{s}\right)$ \\
\hline$V_{\mathrm{pcm}}$ & Volume of metal box $\left(\mathrm{m}^{3}\right)$ \\
\hline \multicolumn{2}{|c|}{ Greek symbols } \\
\hline$\alpha$ & thermal absorption coefficient (dimensionless) \\
\hline$\varepsilon$ & emissivity coefficient (dimensionless) \\
\hline$\rho$ & density $\left(\mathrm{kg} / \mathrm{m}^{3}\right)$ \\
\hline$\sigma$ & Stefan-Boltzmann constant $\left(5.67 \times 10^{-8} \mathrm{~W} / \mathrm{m}^{2} \mathrm{~K}^{4}\right)$ \\
\hline \multicolumn{2}{|c|}{ Subscripts } \\
\hline \multicolumn{2}{|c|}{ delivered delivered } \\
\hline dp & dew point \\
\hline f & fluid \\
\hline i & indoors \\
\hline o & outdoors \\
\hline PCM & phase change material \\
\hline ref & reference \\
\hline S & solid \\
\hline sf & solid to fluid \\
\hline & sky \\
\hline stored & stored \\
\hline sur & surface \\
\hline w & water \\
\hline$\infty$ & ambient \\
\hline
\end{tabular}

the aforementioned benefits. Dutil et al. reviewed (2011) [10] the mathematical modelling and simulations of PCMs and presented various models based on the first and second laws of thermodynamics regarding the problem of melting and solidification for many instances. They also indicated various potential tools that can be useful for determining the potential of PCM use in building applications, including Computer Fluid Dynamics (CFD). They concluded that although models are now established for most applications of PCM materials, the validation of numerical predictions should always be performed by means of the appropriate experimental data.

For more widespread utilisation of PCM in buildings, the benefits of PCM use in building elements must be clarified. This clarification would usually only be possible by conducting analyses that require expertise outside the realm of the designer. This study uses both experimental study and simulation modelling to evaluate the contribution of PCM-integrated building components in the building envelope in terms how much PCM is activated on a daily basis; the results of this study can be used for comparison between various detail, thickness and climate conditions. This paper reports the results of an experimental and simulation study of the use of the selected paraffin-based PCM for summer conditions in a flat roof in the megapolis of İstanbul, Turkey, for different thicknesses of the PCM.

\section{Experimental Work}

The experimental work was performed to provide data to validate the use of the numerical model for simulation purposes. A $50 \mathrm{~cm}$ by $50 \mathrm{~cm}$ physical model of the selected roof detail was constructed to reflect the characteristics of a flat roof. In the experimental setting (Figs. 1 and 2), this roof detail was inserted into an insulated box and subjected to realistic thermal boundary conditions.

The surface temperature of the detail was stabilised by sending conditioned fluid to the upper and lower surfaces of the detail with copper pipes to observe solidification and melting of the PCM contained inside the detail element. The fluid was conditioned in constant temperature water baths. The temperatures in many points of the system were measured via thermocouples (TCs) and resistant temperature detectors - PT 100 - whenever necessary, and the system input/output volumetric flow rate was measured via flow meters. A datalogger transferred the data to the computer, where the data were stored. In addition, a camera observed the PCM and transferred its data to the computer.

\subsection{Experimental Setup}

The box enclosing the model is made of 1.8 -cm-thick compressed fibreboard. The pieces of the box are joined by screws on both sides, whereas the front and upper part of the apparatus is detachable to provide flexibility. To reduce heat loss to the surroundings during the experiment, the surroundings of the box are insulated with extruded polystyrene (XPS) rigid foam of $15-\mathrm{cm}$ thickness (five pieces of $3 \mathrm{~cm}$ ). The front and upper parts are movable. The front part is sealed with the help of four screws, while the upper part closes due to its own weight.

The upper and lower surfaces of the model have separate systems that give to or take energy from the surface. A serpentine coil with conditioned fluid inside helps to reach and maintain the desired surface temperature. During the melting and solidification cycles of the PCM, the fluids are kept at the desired temperatures by the use of circulated water baths. The bath that conditions the fluid to represent the outdoor surface temperature has a capacity of $61,800 \mathrm{~W}$ heating capacity, $140 \mathrm{~W}$ cooling capacity at $0^{\circ} \mathrm{C}, 200 \mathrm{~W}$ cooling capacity at $20^{\circ} \mathrm{C}$ and an operation range between $-40^{\circ} \mathrm{C}$ and $100^{\circ} \mathrm{C}$, whereas the bath that conditions the fluid to represent indoor surface temperature has a volume of $81,1 \mathrm{~kW}$ heating capacity and operation range between $-20^{\circ} \mathrm{C}$ and $100^{\circ} \mathrm{C}$. The volumetric flow of the baths is $15 \mathrm{l} / \mathrm{min}$, and they have a temperature stability of $\pm 0.05^{\circ} \mathrm{C}$ with a reading accuracy of $\pm 0.5^{\circ} \mathrm{C}$.

The conditioned fluid is carried to the building element by highly conductive copper pipes with a $10-\mathrm{mm}$ inner diameter and a wall thickness of $1.5 \mathrm{~mm}$. The heat transfer fluid used in the experiments is water. To ensure even distribution of the energy given to the surfaces and therefore provide a constant surface temperature, the pipes are bent in a serpentine form with staggered outgoing and return lines side by side. The copper tubes outside of the experimental box are insulated with a rubber-based polyurethane pipe coating with a wall thickness of $1 \mathrm{~cm}$.

Four PT-100 type temperature probes measure the inlet and outlet temperatures of the heat transfer fluid. The PT- 100 probes are of Rhodium Platinum/Platinum (pt-rh/pt) type and have an operating temperature range of $-50^{\circ} \mathrm{C}$ to $+150^{\circ} \mathrm{C}$. These probes are immersion type, so as not to obstruct the fluid flow through the pipe. An additional $6 \mathrm{~cm}$ of mineral wool insulation is used to insulate the region between the PT-100 probes and the experimental box to 


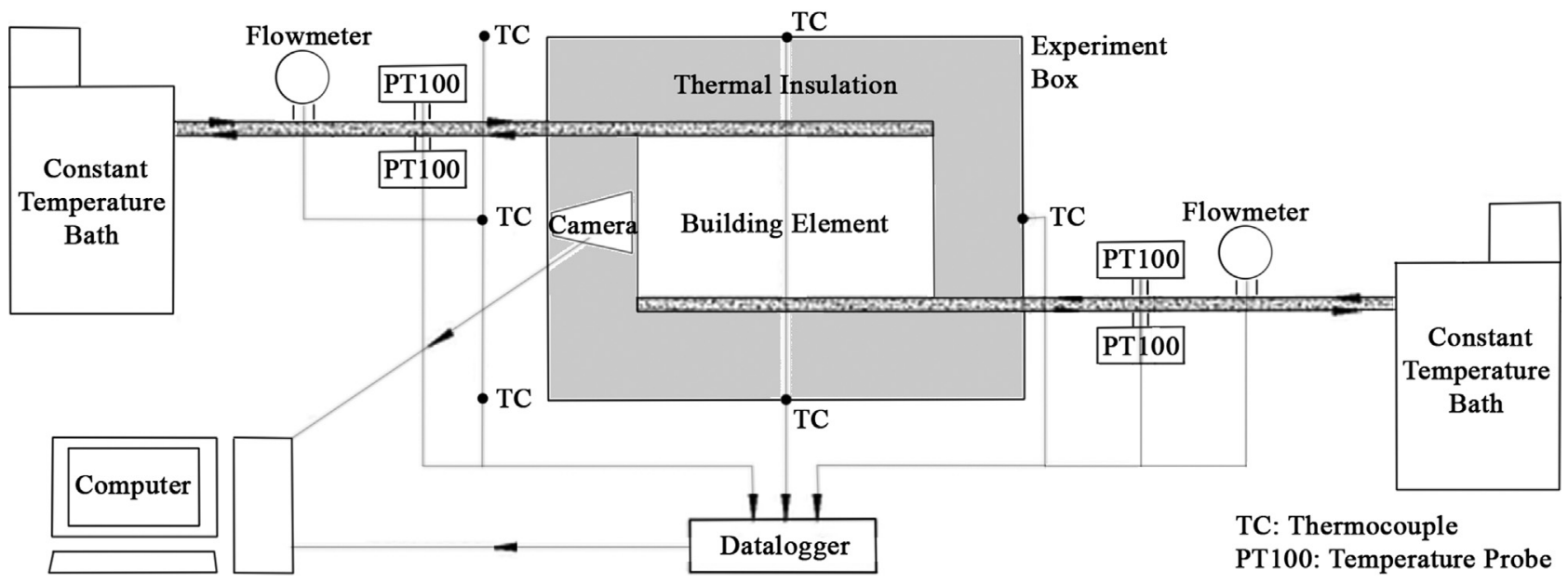

Fig. 1. Scheme of the experimental setup.

further minimise the losses after measuring the temperature of the fluid.

The velocity of the fluid that is delivered to the upper and lower surfaces is measured and collected via electromagnetic flowmeters. The flowmeter has electrodes of $\mathrm{CrNi}$ stainless steel and Hastelloy C276 1.4571 with $0.5 \%$ accuracy in the $0.5-10 \mathrm{~m} / \mathrm{s}$ range and $1 \%$ accuracy in the $0.1-0.5 \mathrm{~m} / \mathrm{s}$ range.

All of the TCs used to measure the temperature in the system are T-type. All of the placements of the TCs, numbering 31 in total, are shown in Fig. 3. To measure the symmetry in the box during heating and/or cooling, TCs are placed symmetrically relative to a plane passing through the centre of the building element. A total of 13 TCs measure the temperature changes occurring in the building element, with TCs 1-3 on the bottom surface of the reinforced concrete slab, TC 4 between the reinforced concrete slab and the thermal insulation, TCs 5-7 between the thermal insulation and the metal box containing the PCM, TCs $8-10$ between the metal box and the water insulation and TCs 11-13 at the top of the ceramic surface. Eleven TCs that are placed at 5-mm intervals (TCs 14-25) read the temperatures regarding the melting and solidification cycles of the PCM. In addition, the surface temperatures of the experimental box (top with TC 26, side with TC 27 and bottom with TC 28) and ambient temperatures of the laboratory (upper with TC 29, middle with TC 30 and below with TC 31) are measured.

The datalogger (Agilent 34972) reads, interprets and translates the millivolt output of the temperature sensors into degrees Celsius with $\pm 0.001^{\circ} \mathrm{C}$ accuracy. The datalogger is connected to a computer via the USB port and outputs the collected data via software prepared by the manufacturer to the computer screen as well as a .csv (comma-separated values) file. Device features include LXI, 3 slots, 6.5 bit - 22 digit - internal Digital Multimeter, 1 GB LAN or USB 2.0 computer connection, graphic web interface and data recording software. One 20-channel $(+2)$ and one 16-channel fixtures are plugged into the slots behind the data collection and switching unit. The fixtures have a speed of 60 channels per second. All data during the experiments was collected in 10-s intervals.

The temperature sensors and the datalogger were calibrated together at the Chamber of Mechanical Engineers Aegean Calibration Laboratory and Metrology Training Center. During the calibration, the water bath at the laboratory (Eurotherm 2216) was set to a fixed temperature, and the provided temperature was read by a 4-channel PT100 probe (S A B Bröckskes D-viersen $4 \times 0.25 \mathrm{~mm}^{2}$ to Liycy) via a multimeter (HP3458 A) every $10 \mathrm{~s}$, and the average values were calculated with a standard deviation. Simultaneous with this operation, the temperature sensors and the datalogger used in the experiment read the same data at the same frequency and standard deviations, and the averages were also calculated. The calibration curves were generated accordingly, and the values measured during the experiments were revised according to these curves using the MATLAB technical computing software.

The detail of the building element is shown in Fig. 3. The main materials used in the detail are reinforced concrete slab $(10 \mathrm{~cm})$, XPS thermal insulation $(6 \mathrm{~cm})$, PCM $(5 \mathrm{~cm})$, waterproofing layer $(1 \mathrm{~cm})$, protective concrete slab $(5 \mathrm{~cm})$, adhesive mortar and ceramic $(1.5 \mathrm{~cm})$. A model with a surface area of $50 \mathrm{~cm} \times 50 \mathrm{~cm}$ was manufactured for the experiment.

The reinforced concrete slab and protective concrete slab were poured in the Dokuz Eylül University Department of Civil

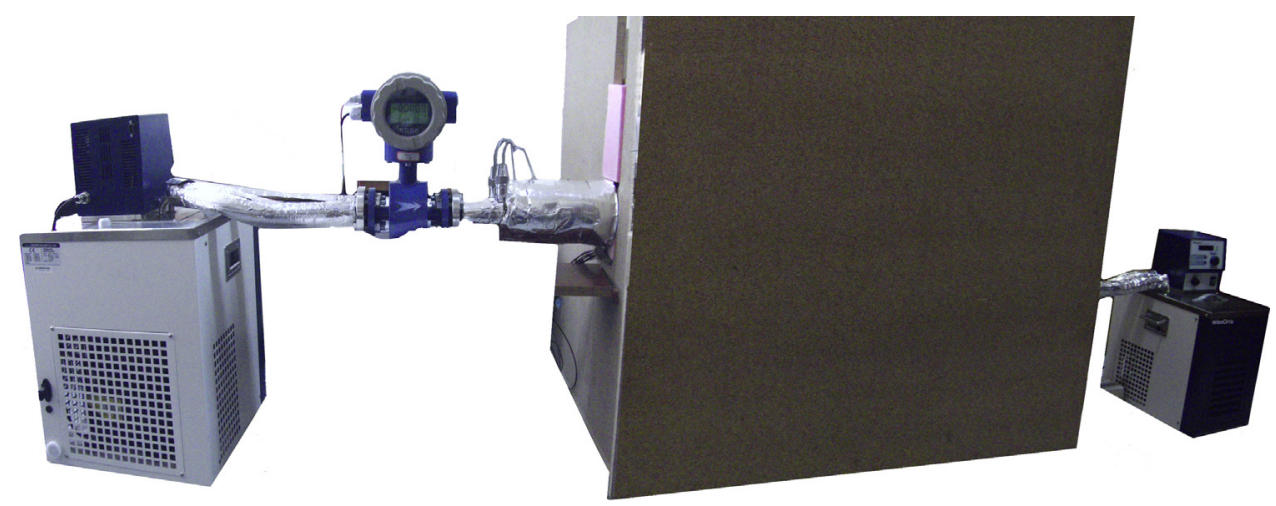

Fig. 2. Photograph of the experimental setup. 


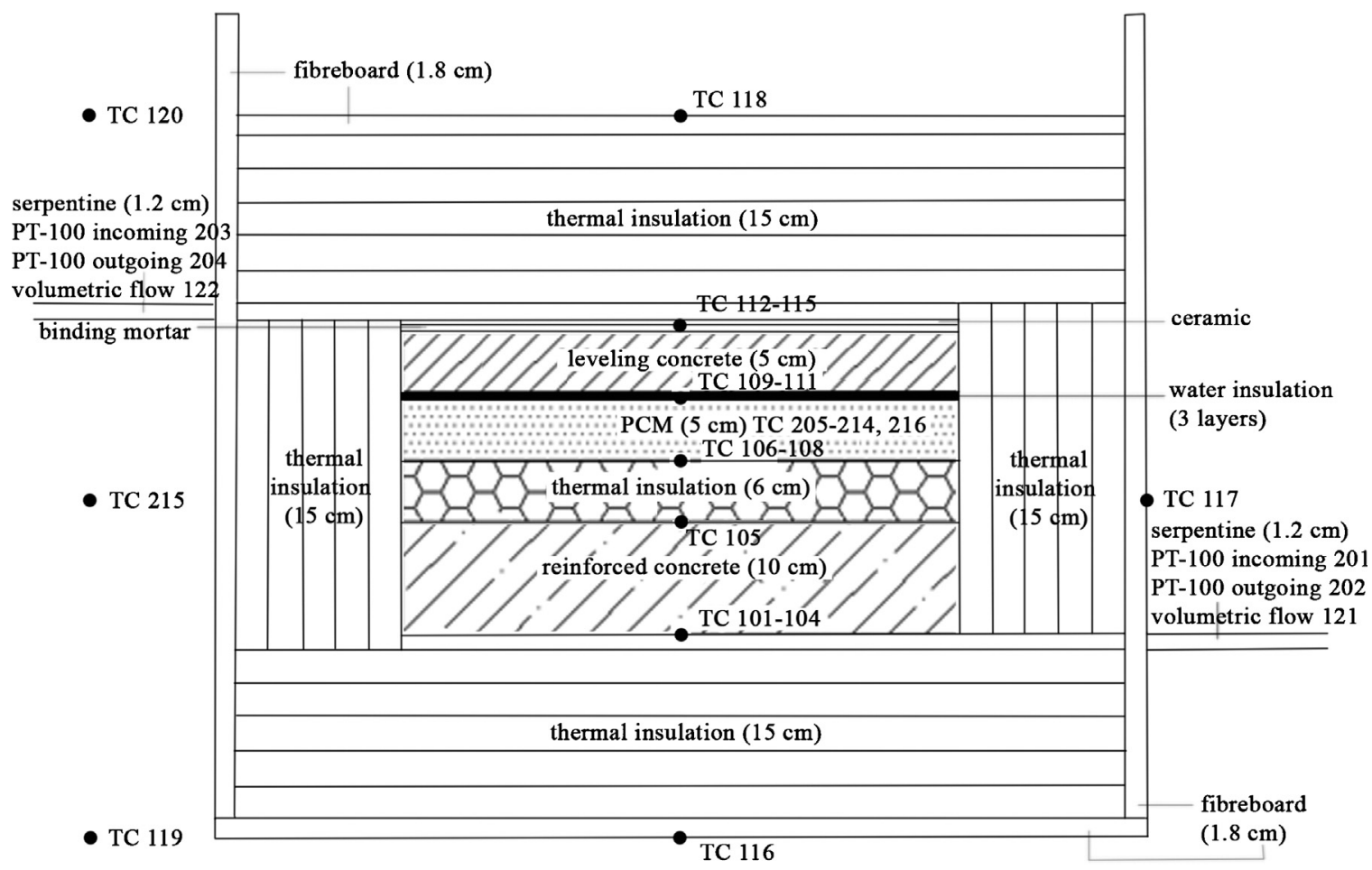

Fig. 3. Thermocouple placements in the experimental box.

Engineering Building Materials Laboratory according to the C20 standard. A $0.05-\mathrm{m}^{3}$ mixture was prepared and poured into moulds of $50 \mathrm{~cm} \times 50 \mathrm{~cm} \times 10 \mathrm{~cm}$ and $50 \mathrm{~cm} \times 50 \mathrm{~cm} \times 5 \mathrm{~cm}$. Four units of $\phi 12$ (48 cm in length) were placed inside the $50 \mathrm{~cm} \times 50 \mathrm{~cm} \times 10 \mathrm{~cm}$ concrete mixture and were used as reinforced concrete, while the $50 \mathrm{~cm} \times 50 \mathrm{~cm} \times 5 \mathrm{~cm}$ piece was used as a protective concrete element. The same thermal insulation as the enclosing box was used in the detail. The thickness of $6 \mathrm{~cm}$ prescribed in the detail was achieved using two pieces of 3-cm XPS boards.

The technical specifications of the selected PCM and RT27 are presented in Table 1 . Because $16 \%$ of the volumetric change was expected during the phase change, PCM was placed in a non-deformable metal container of $50 \mathrm{~cm} \times 50 \mathrm{~cm} \times 5 \mathrm{~cm}$ for the experiment. Before PCM was poured into the metal box, 11 TCs were anchored at $0.5-\mathrm{cm}$ vertical intervals in the centre of the metal box.

To observe the phase change during the experiment, a central portion of the front face of the metal box was cut and replaced with glass. Scales drawn on paper and transparencies were mounted inside the glass. The metal box was carefully balanced so that the PCM would not overflow during the experiment. PCM was poured into the metal box in layers of one-centimetre thickness so that air bubbles would not form during the pouring process. In addition, after pouring the PCM, the balance of the metal box was rechecked. Before starting the experiment, the PCM was melted and solidified three times. A web camera was located inside the heat insulation of the front cover to observe the behaviour of the solid-liquid interface. Data from the camera were recorded in the form of snapshots.

The waterproofing material used is three layers of 3-mm modified bitumen coated on both surfaces by PE film and carried by polyester felt. The aforementioned protective concrete layer, binding mortar and ceramics were placed over the water insulation. After the TCs, copper piping and thermal insulation are placed, and the apparatus is ready.

The experimental uncertainties are calculated by the methodology given in Holman [11] and Ezan et al. [12]. When a measurement is made, the uncertainty in each measurement affects the overall result. Therefore, the overall estimation of the uncertainty for a calculated result $(R)$ is based on the uncertainties of the independent variables $x_{1}, x_{2}, x_{3}, \ldots, x_{n}$, as is shown in Eq. (1).

$R=R\left(x_{1}, x_{2}, x_{3} \ldots x_{n}\right)$

If $\omega_{R}$ is the uncertainty in the result and all of the uncertainties of independent variables are given with the same odds, then the uncertainty in the result can be calculated via Eq. (2).

$\omega_{\mathrm{R}}=\left[\left(\frac{\partial R}{\partial x_{1}} \omega_{1}\right)^{2}+\left(\frac{\partial R}{\partial x_{2}} \omega_{2}\right)^{2}+\ldots+\left(\frac{\partial R}{\partial x_{n}} \omega_{n}\right)^{2}\right]^{1 / 2}$

The energy delivered to the system can be calculated by the enthalpy difference in the inlet and outlet heat transfer fluid (water), as given in Eq. (3).

$E_{\text {delivered }}(t)=\int_{t=0}^{t} \dot{m}_{\mathrm{w}} c_{\mathrm{w}} \Delta T_{\mathrm{w}}(t) d t$

The uncertainties in Eq. (3) may arise from the thermo-physical properties of water $\left(\rho_{\mathrm{w}}\right.$ and $\left.c_{\mathrm{w}}\right)$, the volumetric flowrate measurements $\left(\dot{V}_{\mathrm{w}}\right)$, and the difference between inlet and outlet temperatures $\left(\Delta T_{\mathrm{w}}\right)$. The delivered energy can be written as a function of these variables (Eq. (4)).

$E_{\mathrm{W}}=E\left(t, \rho_{\mathrm{w}}, \dot{V}_{\mathrm{w}}, c_{\mathrm{w}}, \Delta T_{\mathrm{w}}\right)$

The total energy stored in the system contains latent and sensible thermal components and can be calculated as in Eq. (5).

$$
\begin{aligned}
\Delta E_{\text {stored }}(t)= & m_{\mathrm{PCM}}(t) h_{\mathrm{sf}}+[m(t) c \Delta T(t)]_{\mathrm{PCM}, \mathrm{s}} \\
& +[m(t) c \Delta T(t)]_{\mathrm{PCM}, \mathrm{f}}
\end{aligned}
$$

The independent variables in Eq. (5) that may cause uncertainties are the geometry of the storage tank, the temperature measurement sensors, and the thermo-physical properties of the 
Table 1

Technical specifications of RT27 [19].

\begin{tabular}{|c|c|c|c|}
\hline Melting area $\left({ }^{\circ} \mathrm{C}\right)$ & $25-28$ & Density at $15^{\circ} \mathrm{C}$ (solid) $\mathrm{kg} / \mathrm{l}$ & 0.88 \\
\hline Typical melting point $\left({ }^{\circ} \mathrm{C}\right)$ & 27 & Density at $40^{\circ} \mathrm{C}$ (liquid) $\mathrm{kg} / \mathrm{l}$ & 0.76 \\
\hline Solidification area $\left({ }^{\circ} \mathrm{C}\right)$ & $28-25$ & Volume expansion & $16 \%$ \\
\hline Typical solidification point $\left({ }^{\circ} \mathrm{C}\right)$ & 27 & Heat conductivity ( $\mathrm{W} / \mathrm{m} \mathrm{K})$ & 0.2 \\
\hline Heat storage capacity $(\mathrm{kJ} / \mathrm{kg})$ & 179 & Kinetic viscosity $\left(50^{\circ} \mathrm{C}\right) \mathrm{mm}^{2} / \mathrm{s}$ & 26.32 \\
\hline Flash point $\left({ }^{\circ} \mathrm{C}\right)$ & 146 & Water hazard class (WGK) & 1 \\
\hline Corrosion & Is not chemically reactive with most materials & & \\
\hline
\end{tabular}

PCM in solid and liquid states $\left(\rho_{\mathrm{pcm}, \mathrm{l}}, \rho_{\mathrm{pcm}, \mathrm{s}}, c_{\mathrm{pcm}, \mathrm{l}}, c_{\mathrm{pcm}, \mathrm{s}}\right.$ and $\left.h_{\mathrm{sf}}\right)$. Therefore, the total energy stored in the system can be written as Eq. (6).

$E_{\text {stored }}=E\left(t, h_{\mathrm{sf}}, V_{\mathrm{pcm}}, \rho_{\mathrm{pcm}, \mathrm{s}-\mathrm{f}}, c_{\mathrm{pcm}, \mathrm{s}-\mathrm{f}}, \Delta T_{\mathrm{pcm}, \mathrm{s}-\mathrm{f}}\right)$

The uncertainties of the individual variables are presented in Table 2. The overall uncertainty for the energy calculations in Eqs. (4) and (6) can be written in partial derivatives as in Eq. (2). The resulting uncertainties for the total delivered and stored energies are calculated as \pm 0.6 percent and \pm 7.7 percent, respectively.

\subsection{The experiment}

Prior to the experiments, the apparatus was run without any PCM and the energy balance was checked. In addition, the sensible heat capacity and system losses were calculated for the roof model with no latent heat. Next, the PCM was placed and the experiment was run. Thus, the thermal behaviour and the latent heat storage capacity of the model were analysed via the temperature measurements, energy calculations, graphs, and observation snapshots.

Before the start of an experiment, fluid at a temperature of $25^{\circ} \mathrm{C}$ was passed from the top and bottom serpentines until all of the measured temperatures inside the building element reached $25^{\circ} \mathrm{C}$ and the PCM was completely solid. During the experiment, the temperature inside the laboratory was set at $25^{\circ} \mathrm{C}$ to reduce the probable heat losses from the system. Measurements were taken while the temperature of the surface representing the interior was kept constant, at $25^{\circ} \mathrm{C}$, and the surface temperature representing the outside reached and stayed at $50^{\circ} \mathrm{C}$. Later, this experiment was repeated under the same conditions. Changes in the thermophysical properties of the heat transfer liquid were also considered during the calculations. The numerical difference between the energy calculations of the two experiments was $0.33 \%$. Moreover, the experiment was repeated with two different outside surface temperatures of $40^{\circ} \mathrm{C}$ and $60^{\circ} \mathrm{C}$. The PCM temperatures measured during the experiment are given in Fig. 4. The temperatures measured during the experiments for different outside surface temperatures of the top and bottom surfaces as well as the middle of the PCM (PCM 5) are given in Fig. 5. All of the experimental data can be reached from [20].

At the beginning of the experiment, the entire building element is at equilibrium. During the experiment, the top and bottom surface temperatures were kept constant and phase change occurred until a new equilibrium was reached. Four consecutive states of the PCM were read from the temperatures measured during the experiment (Figs. 4 and 5). First, until the temperature of the PCM reached the phase change temperature, energy storage primarily occurred in the form of sensible energy storage; therefore, the temperature of the PCM gradually increased. During the phase change, the slope of the PCM temperatures reduced, and the main energy storage type was latent heat. Third, following the phase change, the PCM temperature increased until the building element reached a steadystate temperature distribution and the PCM once again stored heat sensibly. Finally, the PCM as well as the other materials in the model reached steady-state and their temperatures remained constant.
The phase change interface was identified by observing the camera pictures. Fig. 6 shows the interface and some of the pictures. The solid state of the PCM occupied $4.4 \mathrm{~cm}$ of the 5 -cm-thick metal box, so that when the PCM melted, it would increase in volume and occupy the entire 5-cm height. Therefore, at the start of the experiment, the PCM thickness was $4.4 \mathrm{~cm}$. As the PCM melted, the interface continuously decreased in accordance with expectations. However, the observations indicated that the entire surface of the PCM did not move in unison; instead, the edges changed phase more rapidly, i.e., the centre was slightly more elevated during melting.

\section{Numerical Modelling}

The numerical model chosen in this study is finite volume analysis, and the commercial software ANSYS FLUENT was used to obtain solutions [13]. In finite volume analysis, after the geometry is defined, the volume is divided into control volumes, and main equations representing the flow are solved for each control volume. The main equations are mass, energy and momentum conservation. The process first requires these equations to be integrated into the mesh, and then the integral equations are converted into algebraic equations; subsequently, the algebraic equations are solved iteratively.

FLUENT analysis is performed for a planar building element, i.e., a flat roof, which has one air-conditioned surface (indoors), while the other surface is under the influence of ambient conditions (outdoors). To simplify the analysis, the following assumptions are made:

- Heat transfer in the element is one-dimensional.

- The thermophysical properties of the materials used are constant, except for the PCM during phase change, where the specific heat changes.

- Only the transmission effect is considered in the PCM; in other words, the natural convection effect in the PCM during the melting process and the supercooling effect during the freezing processes are neglected.

According to these assumptions, only the energy equation is resolved in FLUENT,

$\frac{\partial}{\partial t}(\rho H)=\frac{\partial}{\partial x}\left(k \frac{\partial T}{\partial x}\right)+\frac{\partial}{\partial y}\left(k \frac{\partial T}{\partial y}\right)$

In Eq. (7), $\rho$ is the density of the building materials, $H$ is the enthalpy, and $k$ is their thermal conductivity. $H$ represents both the sensible and latent enthalpy. The sensible enthalpy $(h)$ is expressed in Eq. (8), where $h_{\text {ref }}$ is the reference enthalpy at the reference temperature $T_{\text {ref }}[14]$.

$h=h_{\mathrm{ref}}+\int_{T_{\mathrm{ref}}}^{T} c \Delta T$ 
Table 2

Uncertainties of the independent variables.

\begin{tabular}{|c|c|c|c|}
\hline Variable & Value & Uncertainty & Comment \\
\hline Density of water, $\rho_{\mathrm{w}}$ & $997 \mathrm{~kg} / \mathrm{m}^{3}$ for $25^{\circ} \mathrm{C}$ & $\pm 0.02 \%$ & $\begin{array}{l}\text { Uncertainty arises from the selection of the thermo-physical } \\
\text { properties of the heat transfer fluid }\end{array}$ \\
\hline Specific heat of water, $c_{\mathrm{w}}$ & $4180 \mathrm{~J} / \mathrm{kg} \mathrm{K}$ for $25^{\circ} \mathrm{C}$ & $\pm 0.3 \%$ & \\
\hline Volumetric flow rate, $\dot{V}_{\mathrm{w}}$ & $0.00002-5 \mathrm{~m}^{3} / \mathrm{s}$ & $\pm 0.5 \%$ & Uncertainty arises from the volumetric flow rate measurement \\
\hline Temperature differences, $\Delta T_{\text {water }}$ & $0-100^{\circ} \mathrm{C}$ & $\pm 0.02 \%$ & Uncertainty arises from the Pt-100 measurements [22] \\
\hline Density of the liquid PCM, $\rho_{\mathrm{pcm}, \mathrm{l}}$ & $0.76 \mathrm{~kg} / \mathrm{l}$ & $\pm 0.02 \%$ & $\begin{array}{l}\text { Uncertainty arises from the selection of the thermo-physical } \\
\text { properties of the PCM [19] }\end{array}$ \\
\hline Density of the solid PCM, $\rho_{\mathrm{pcm}, \mathrm{s}}$ & $0.88 \mathrm{~kg} / \mathrm{l}$ & $\pm 0.02 \%$ & \\
\hline Specific heat of the liquid PCM, $c_{\mathrm{pcm}, 1}$ & $2 \mathrm{~kJ} / \mathrm{kg} \mathrm{K}$ & $\pm 0.3 \%$ & \\
\hline Specific heat of the solid PCM, $c_{\mathrm{pcm}, \mathrm{s}}$ & $2 \mathrm{~kJ} / \mathrm{kg} \mathrm{K}$ & $\pm 0.3 \%$ & \\
\hline Latent heat, $h_{\mathrm{sf}}$ & $179 \mathrm{~kJ} / \mathrm{kg}$ & Neglected & \\
\hline Position of the thermocouple, $p$ & $5 \mathrm{~mm}$ & $\pm 0.5 \mathrm{~mm}$ & Uncertainty arises from thermocouple positioning \\
\hline Volume of the metal box, $V_{\mathrm{pcm}}$ & $0.0125 \mathrm{~m}^{3}$ & $\pm 1 \%$ & Uncertainty arises from the geometry of the storage \\
\hline Temperature measurements, $T_{\mathrm{pcm}}$ & $0-60^{\circ} \mathrm{C}$ & $\pm 0.035 \%$ & Uncertainty arises from the thermocouple measurements [22] \\
\hline
\end{tabular}

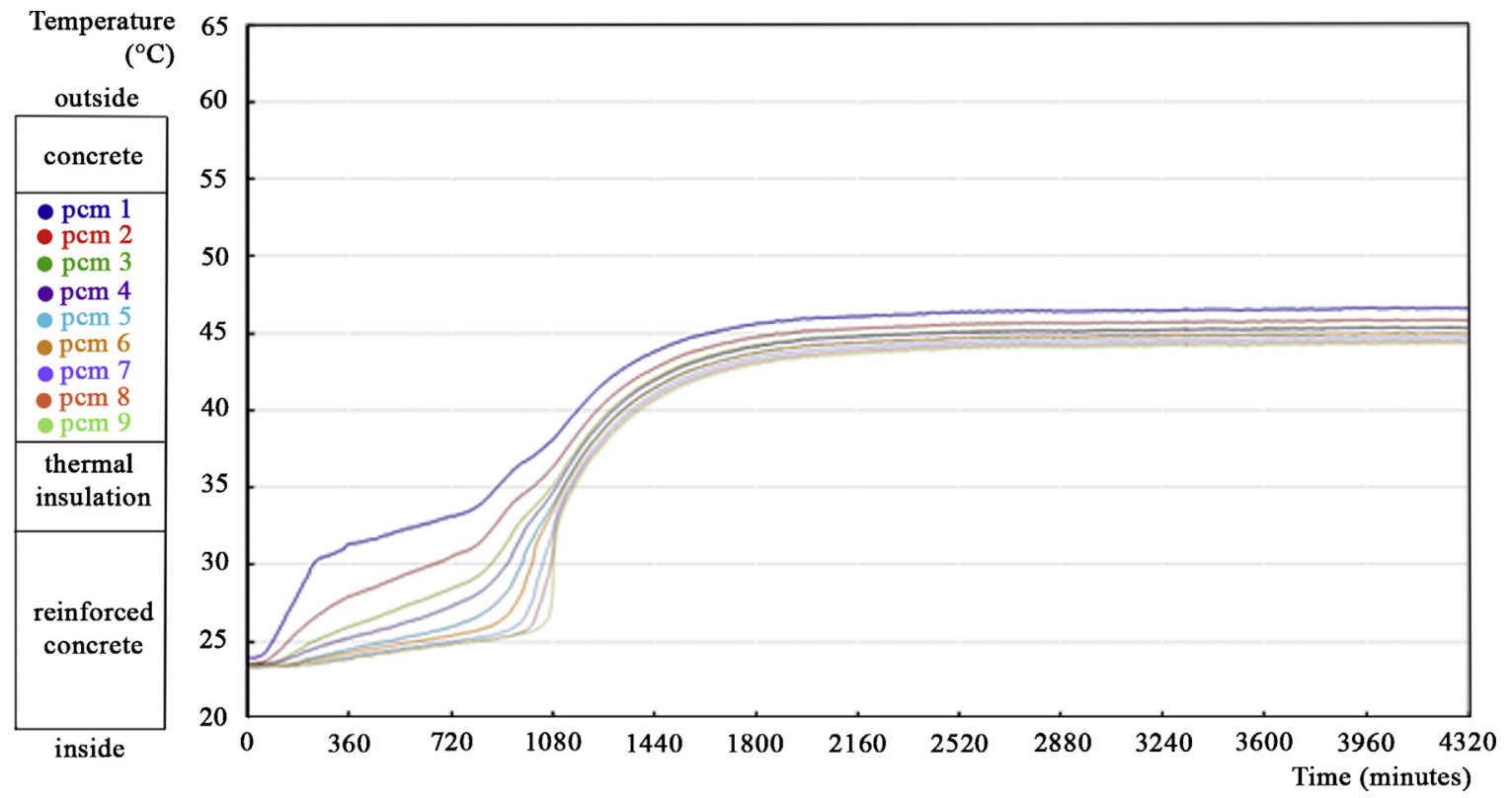

Fig. 4. The PCM temperatures measured during the experiment.

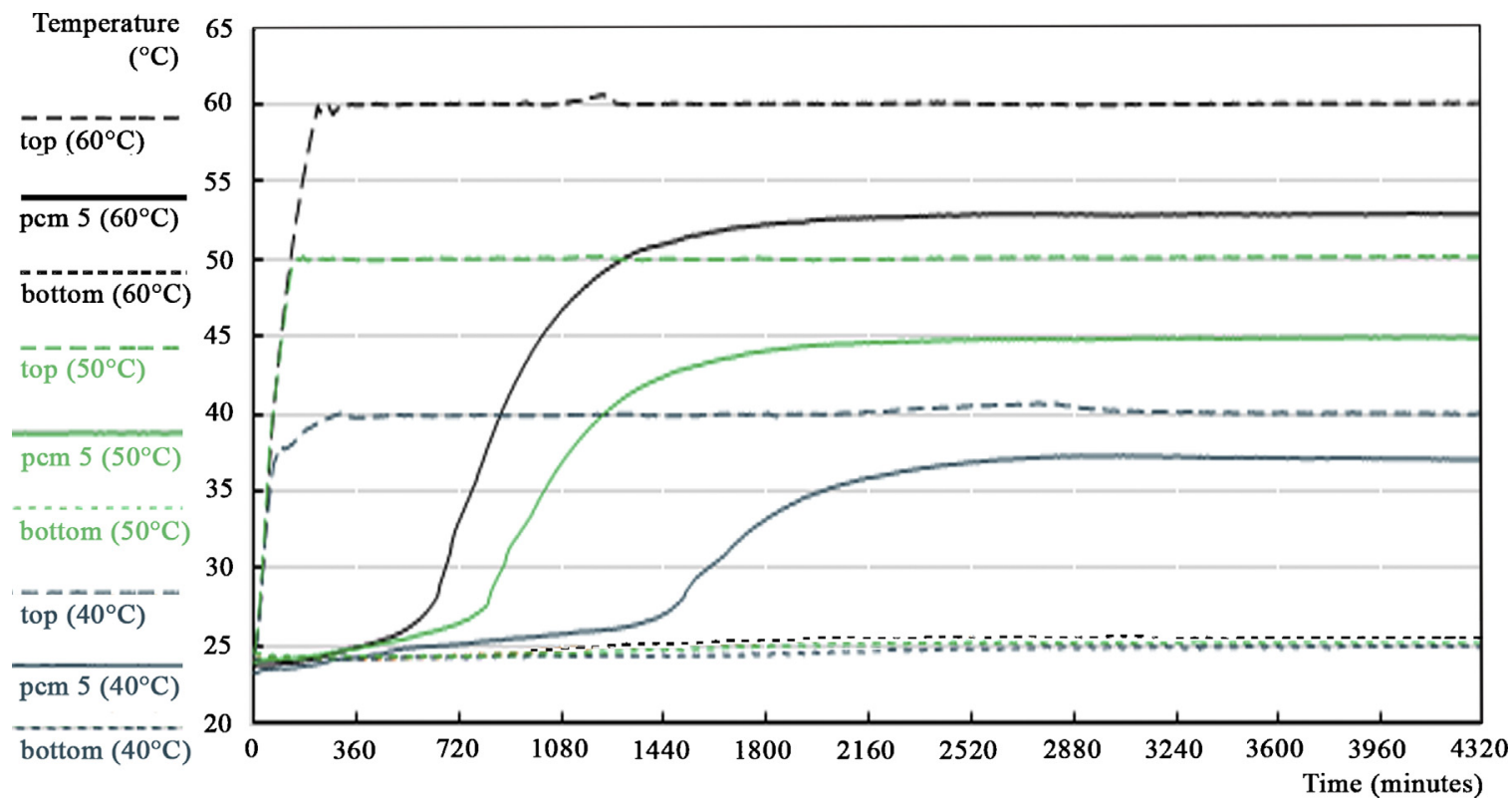

Fig. 5. Temperatures measured during the experiments for $40^{\circ} \mathrm{C}, 50^{\circ} \mathrm{C}$ and $60^{\circ} \mathrm{C}$. 


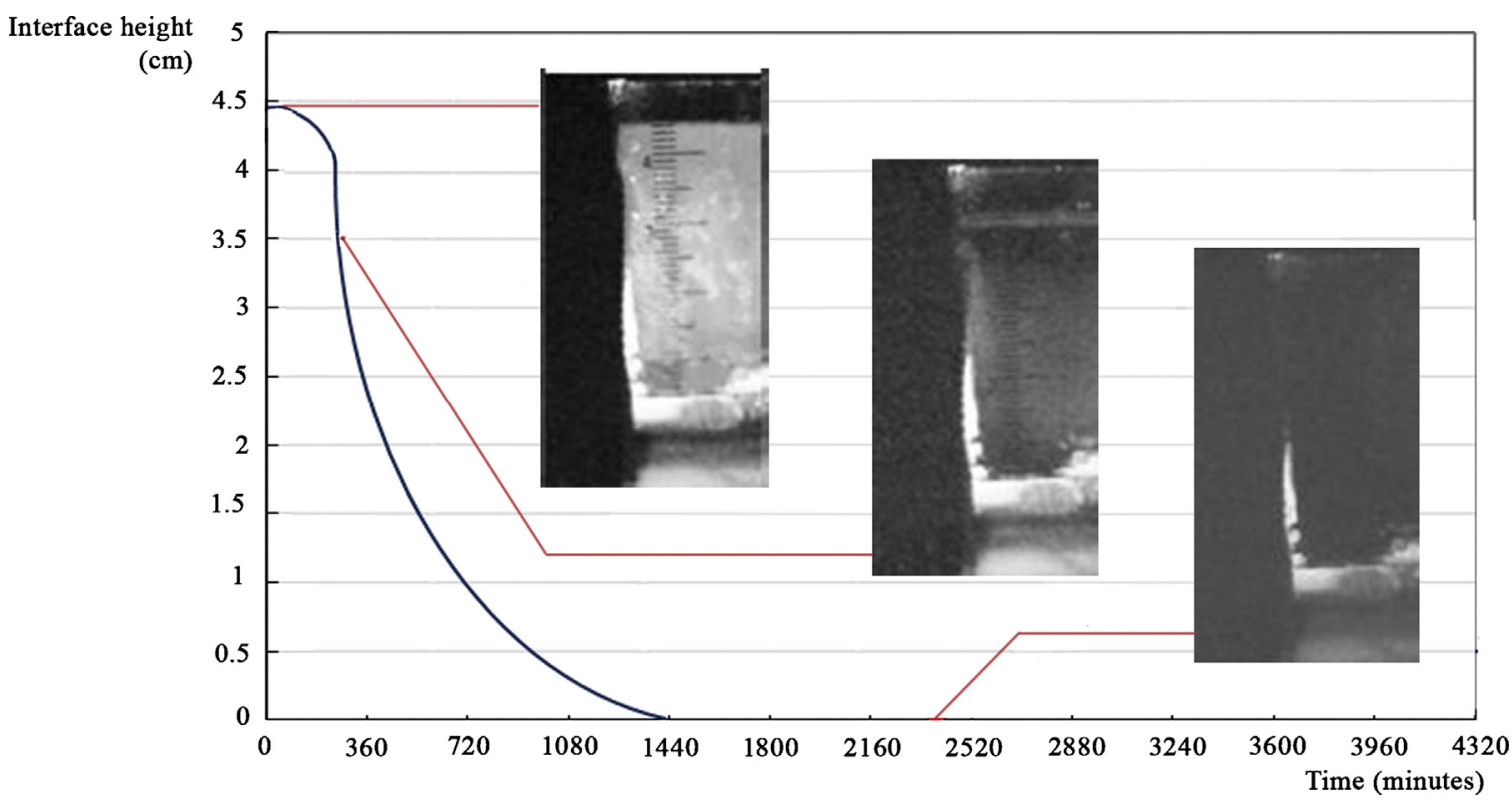

Fig. 6. Phase change interface.

$H$ can be expressed with both sensible and latent terms as in Eq. (9). Here, $h_{\mathrm{sf}}$ represents the latent heat content of the PCM that may change between solid and liquid.

$H=h+h_{\mathrm{sf}}$

The Geometry \& Mesh Building Intelligent Toolkit (GAMBIT) is used to construct the flow geometry and the necessary mesh for solving the equations, the phase of the regions and the boundary conditions. Next, the model was converted into a two-dimensional mesh that FLUENT can read. To ensure a reasonable calculation time, the geometry was defined for a $10-\mathrm{cm}$ cross-section. Because the mesh quality affects the quality of the solutions, three different mesh size values were studied for the selection of the mesh used in this study. The first case is the base case in which the mesh had 2880 cells and the size for materials aside from the PCM was $0.25 \mathrm{~cm} \times 0.25 \mathrm{~cm}$, and $0.25 \mathrm{~cm} \times 0.1 \mathrm{~cm}$ for the PCM. The second case has 1440 cells with $0.5 \mathrm{~cm} \times 0.5 \mathrm{~cm}$ size for materials aside from the PCM, and $0.5 \mathrm{~cm} \times 0.2 \mathrm{~cm}$ for the $\mathrm{PCM}$; the results of the second case differ by $0.63 \%$ from the base case. The third case has 285 cells and $1 \mathrm{~cm} \times 1 \mathrm{~cm}$ size for materials aside from the PCM, and $1 \mathrm{~cm} \times 0.4 \mathrm{~cm}$ for the PCM; the results of the third case differ by $5.23 \%$ from the base case. Consequently, the second case is selected. Both the mesh and grid orientation are as shown in Fig. 7.

Material properties are defined into FLUENT as in Table 3. The PCM is defined as having a thickness of $5 \mathrm{~cm}$. Because the mass of the material must be constant during the melting and solidification cycles, the liquid volumetric mass value provided by the manufacturer was used for both the solid and liquid state. The melting and solidification temperature of the PCM are not constant but occur over a temperature range; therefore, a phase change temperature range of $0.5^{\circ} \mathrm{C}$, between $25.72{ }^{\circ} \mathrm{C}$ and $26.22^{\circ} \mathrm{C}$, is assumed. The sensible heat value is $2400 \mathrm{~J} / \mathrm{kg} \mathrm{K}$, and the latent heat value is $139,000 \mathrm{~J} / \mathrm{kg}$. The latent heat value that is used in the simulation is $40,000 \mathrm{~J} / \mathrm{kg}$ lower than the commercially given value of $179,000 \mathrm{~J} / \mathrm{kg}$. Yet, the measurements are consistent with both the experiments and measurements of Sheth Karathia [15], who studied three RT27 samples and measured their specific heat via differential scanning calorimetry for three cycles. During the phase change, the PCM stores both sensible and latent heat; thus, $280,400 \mathrm{~J} / \mathrm{kg} \mathrm{K}$ of $c_{\mathrm{p}}$ is defined as the material properties of the PCM between $25.72{ }^{\circ} \mathrm{C}$ and $26.22^{\circ} \mathrm{C}$.

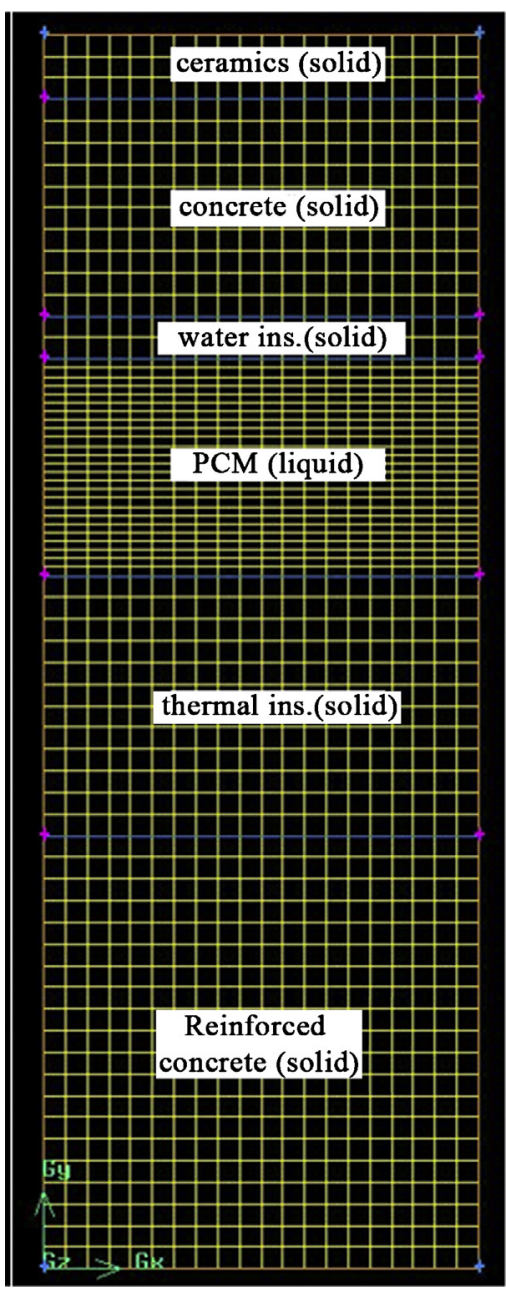

Fig. 7. Geometry and meshing with GAMBIT.

The cell zone conditions were defined in GAMBIT as liquid for the PCM and solid for the other materials. In addition, the boundary conditions were defined as walls; however, the sides of the experimental unit are defined as symmetric. The experimental 
Table 3

Material properties in FLUENT.

\begin{tabular}{|c|c|c|c|}
\hline Material or element type & Mass per unit volume $\left[\mathrm{kg} / \mathrm{m}^{3}\right]$ & Thermal conductivity [W/mK] & Specific heat $[\mathrm{J} / \mathrm{kgK}]$ \\
\hline Ceramic (and binding mortar) & 1750 & 1.45 & 879 \\
\hline Concrete & 2200 & 1.1 & 850 \\
\hline Water insulation (three layers) & 1200 & 0.19 & 920 \\
\hline \multirow[t]{2}{*}{ PCM } & 760 & 0.2 & 2400 \\
\hline & & & $280,400^{a}$ \\
\hline XPS board (two layers) & 25 & 0.035 & 1213 \\
\hline Reinforced concrete & 2400 & 1.2 & 920 \\
\hline
\end{tabular}

a During phase change-between $25.72{ }^{\circ} \mathrm{C}$ and $26.22^{\circ} \mathrm{C}$.

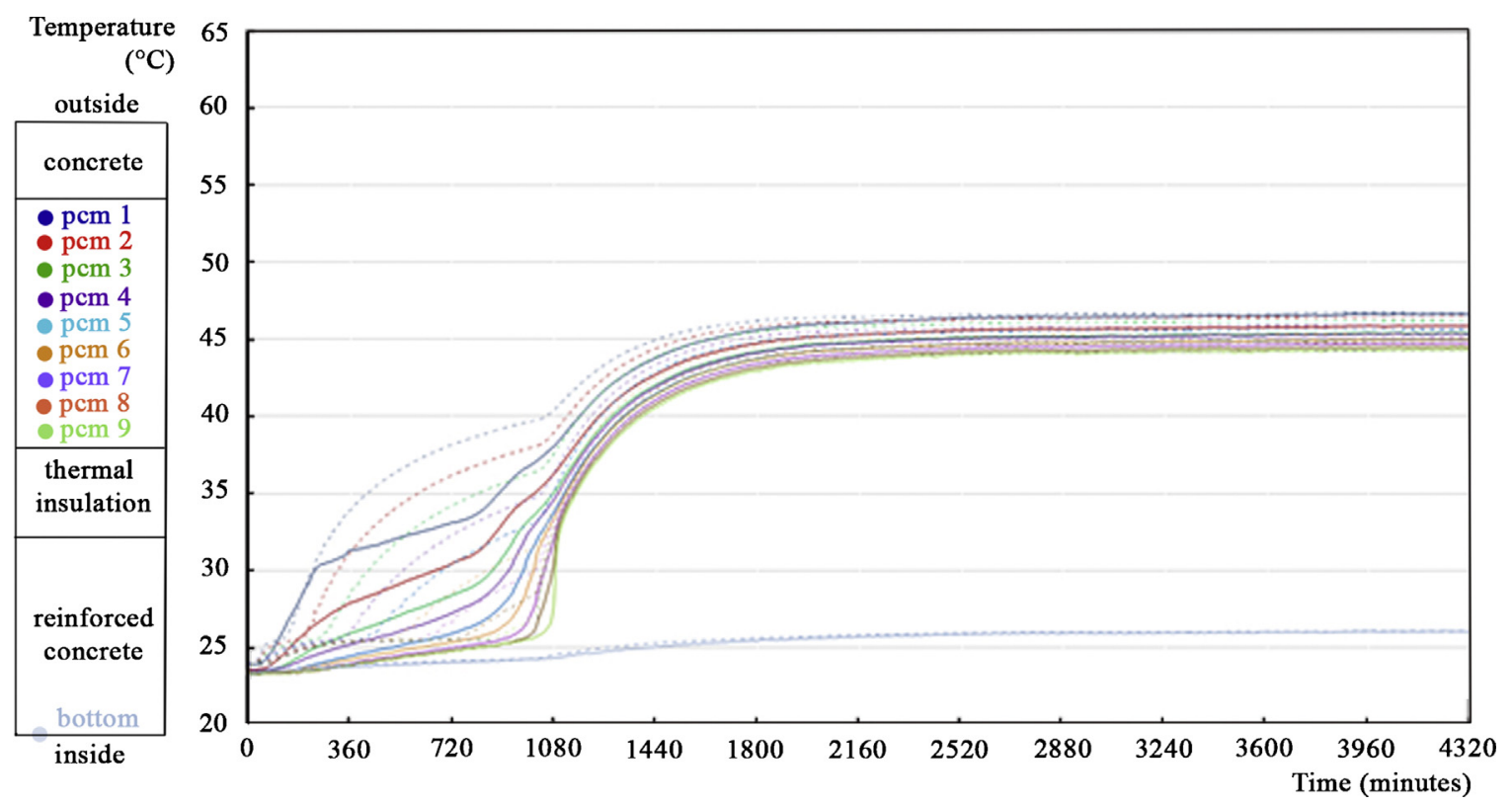

Fig. 8. Experimentally measured (continuous lines) and numerically calculated (dashed lines) temperature results in PCM.

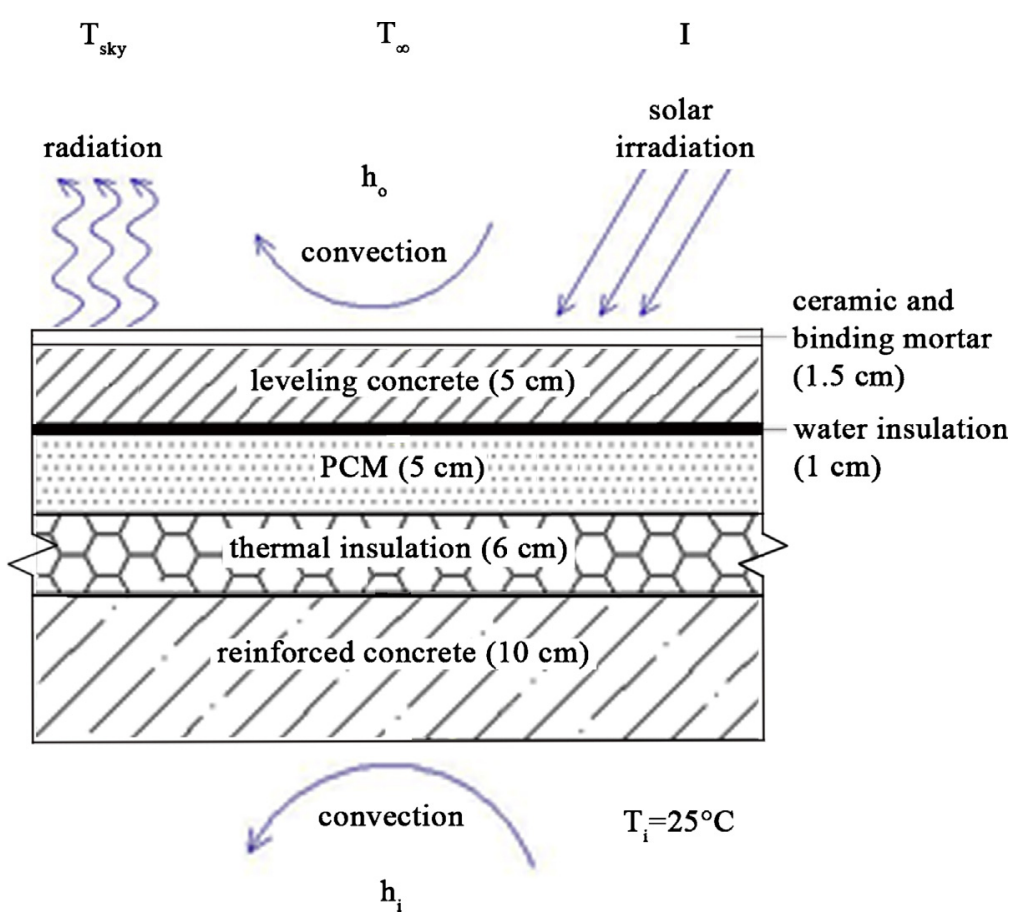

Fig. 9. Boundary conditions for the simulation. 


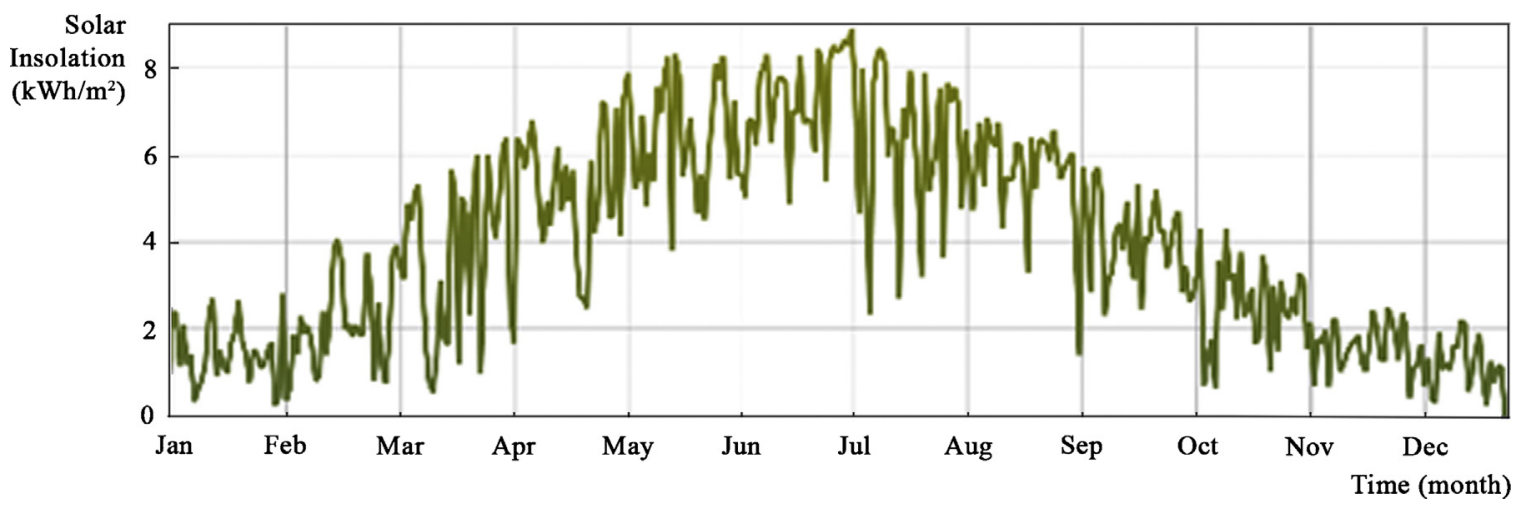

Fig. 10. Insolation values of İstanbul for a year.

temperature measurements taken from the upper and lower surfaces are identified as time-dependent user-defined functions [13].

The problem is solved in the digital environment using a twodimensional double precision solver. After reading the mesh, the energy module is opened. During the selection of the convergence criteria, four cases were compared, and $10^{-10}$ convergence is chosen for the energy. After this process, the solution was launched. During the solution, a constant time step of 300 s was used. When determining the time-step, the simulation was performed for three differing values. In addition, the convergence value was also chosen among three values.

The temperature results for both the experiment and numerical simulation are shown in Fig. 8. The difference between the experimental and simulation work is calculated as $0.28 \%$ for the case without PCM and 5.30\% for the case with PCM. Moreover, the best fit between the measured and simulated temperature results is observed at the reinforced concrete slab and the XPS because the sensible heat is more dominant in these layers. Although the layers in direct contact with the PCM show significant similarities in their temperature curves, they do not exactly coincide.

The analysis of the numerical results confirmed the accuracy of the proposed model. Some differences are found between the final temperatures reached in the experimental measurements and the final temperatures in the numerical results. Possible causes for these differences include the following: the basic assumptions of the natural convection effect inside of the PCM; the aggregation of thermal conductivity values in the PCM (the metal box and the air gap between the box and the PCM were aggregated); the differences resulting from the thermophysical properties of the materials; the differences arising from the chosen mesh size; numerical differences regarding errors from long calculation times; neglecting the volumetric change occurring between the solid and liquid states of the PCM; and neglecting the experimental system losses, despite all the measures taken to insulate the apparatus. However, a fit of approximately $5 \%$ is sufficient for the purpose of this study.

\section{Simulation for Istanbul}

\subsection{Simulation and calculation method}

The simulation validated above for the flat roof element can be used to optimise the design of the element for various details and applications. In this study, the simulation is performed to evaluate the benefits of using different PCM thicknesses for the purpose of cooling in an air-conditioned room set at a constant temperature of $25^{\circ} \mathrm{C}$ from May to September in İstanbul, Turkey. For this implementation, the boundary conditions should be correctly defined in the numerical model. For the outdoors, convection, radiation, and conduction inside the element are considered. For the indoors, constant temperature and convection are defined. The boundary conditions are shown in Fig. 9.

The boundary conditions for the outdoor surface are calculated using the formula given in Eq. (10).

$\kappa \frac{\frac{\partial T}{\partial x}}{x=0}=\alpha I+\sigma \varepsilon\left(T_{\text {sur }}^{4}-T_{\text {sky }}^{4}\right)+h_{0}\left(T_{\text {sur }}-T_{\infty}\right)$

In this equation: $\alpha$ is the thermal absorption coefficient [dimensionless], $I$ is the solar irradiation incident per unit surface area $\left[\mathrm{W} / \mathrm{m}^{2}\right], \sigma$ is the Stefan-Boltzmann constant $\left[5.67 \times 10^{-8} \mathrm{~W} / \mathrm{m}^{2} \mathrm{~K}^{4}\right], \varepsilon$ is the emissivity coefficient [dimensionless], $T_{\text {sur }}$ is the surface temperature $[\mathrm{K}], T_{\text {sky }}$ is the sky temperature $[\mathrm{K}], h_{\mathrm{o}}$ is the thermal convection coefficient for the outdoors $\left[\mathrm{W} / \mathrm{m}^{2} \mathrm{~K}\right]$, and $k$ is the thermal conductivity [W/mK]. In Eq. (10), the absorption coefficient $(\alpha)$ and $\varepsilon$ values are surface characteristics.

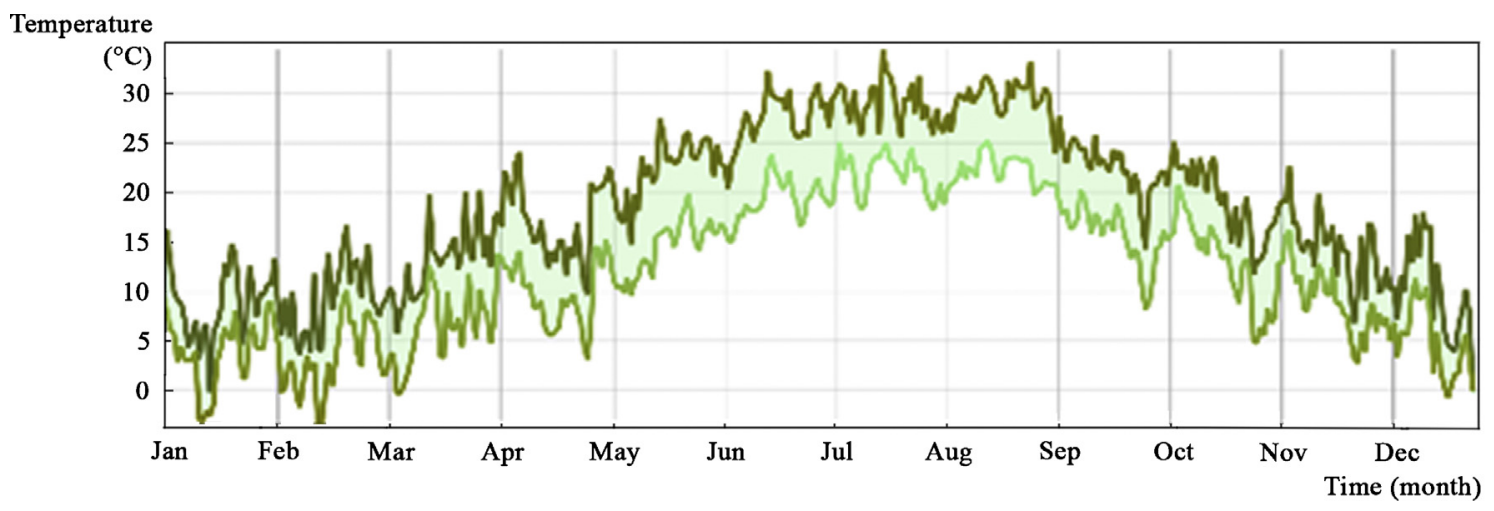

Fig. 11. Maximum and minimum temperatures of İstanbul for a year. 


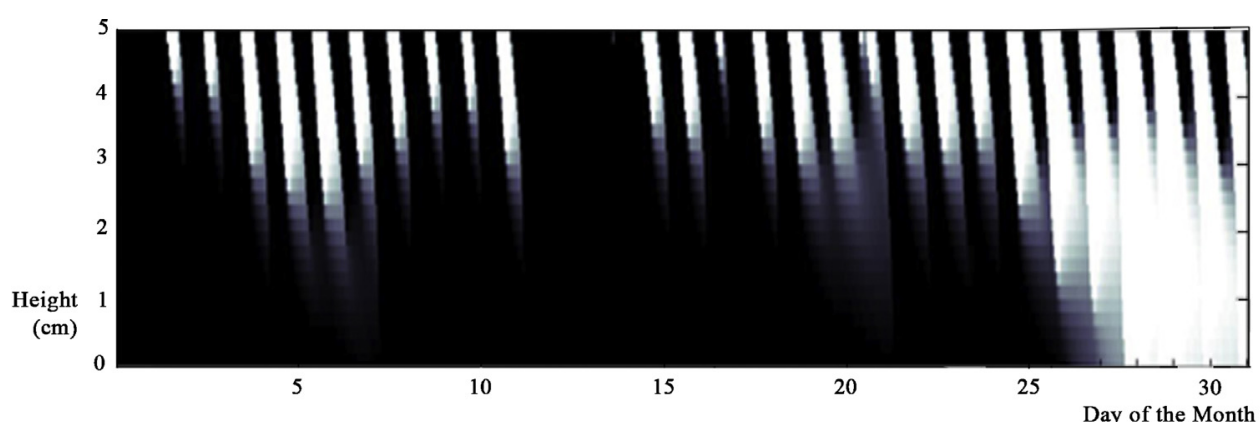

a) $5 \mathrm{~cm}$ PCM in May

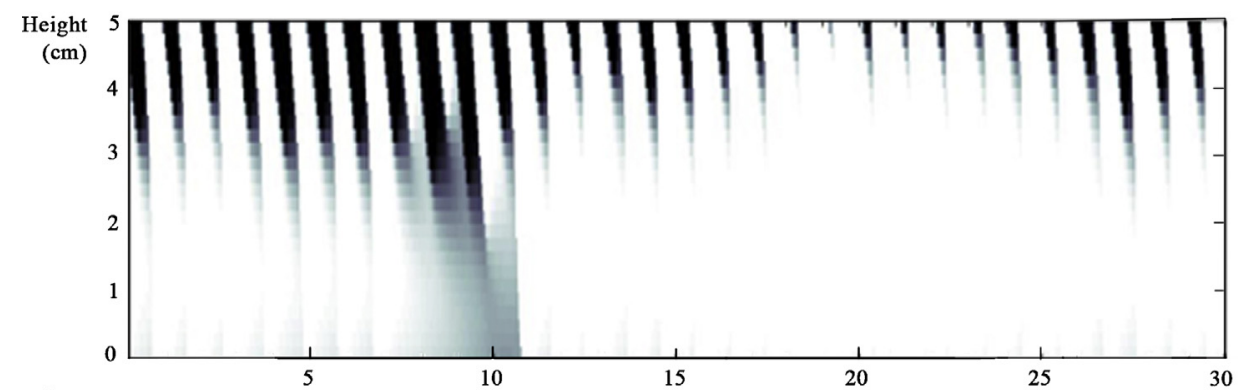

a) $5 \mathrm{~cm}$ PCM in June

Day of the Month

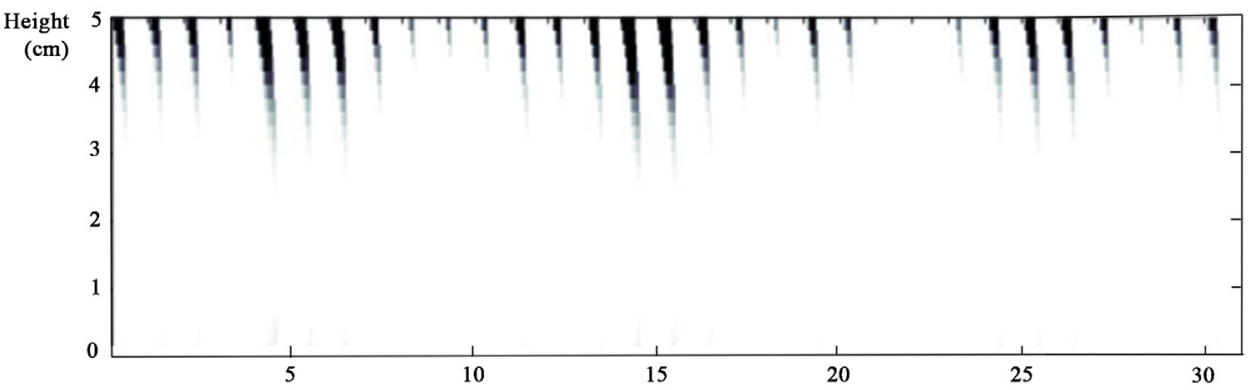

a) $5 \mathrm{~cm}$ PCM in July

Day of the Month
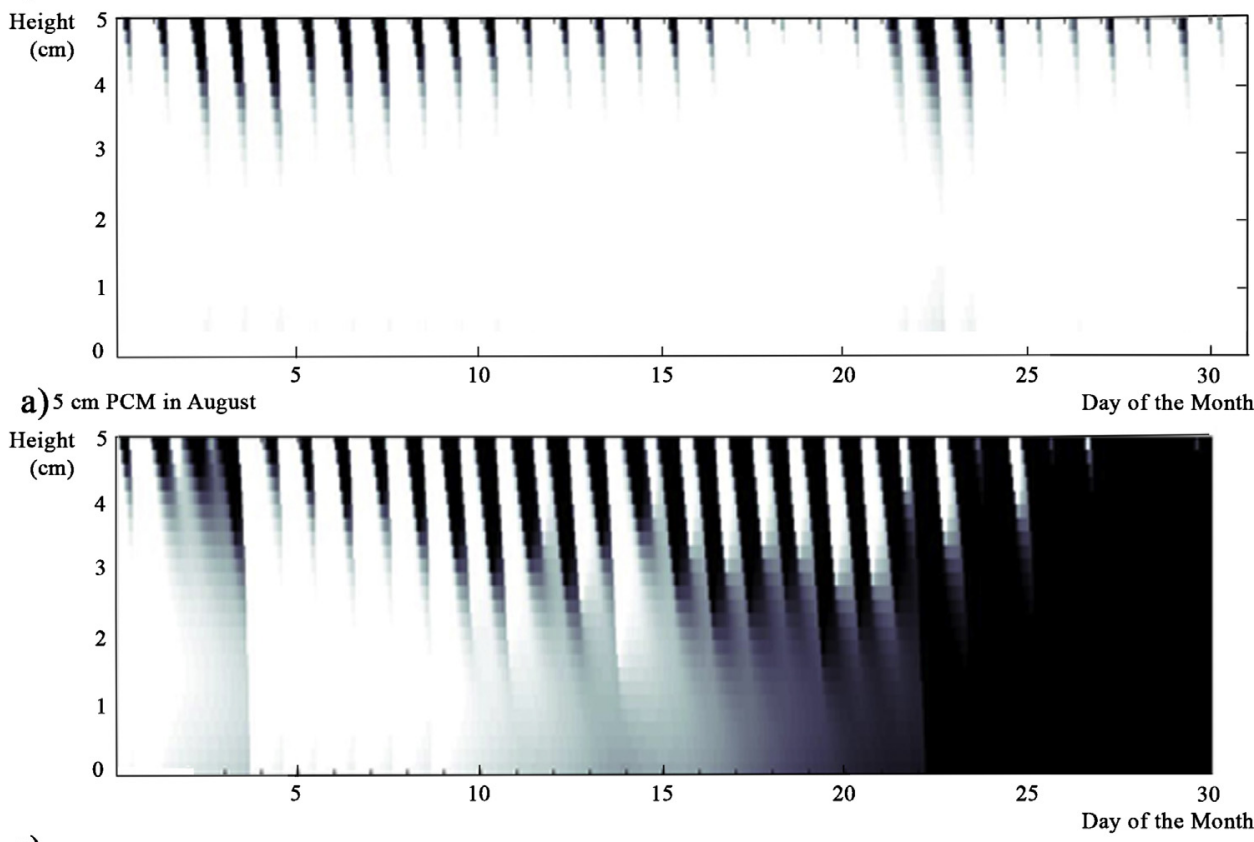

a) $5 \mathrm{~cm} \mathrm{PCM}$ in September

Fig. 12. Solid-liquid state of the PCM in İstanbul from May to September (black denotes solid, whereas white represents liquid, and the darkness of grey indicates the level of transition). 


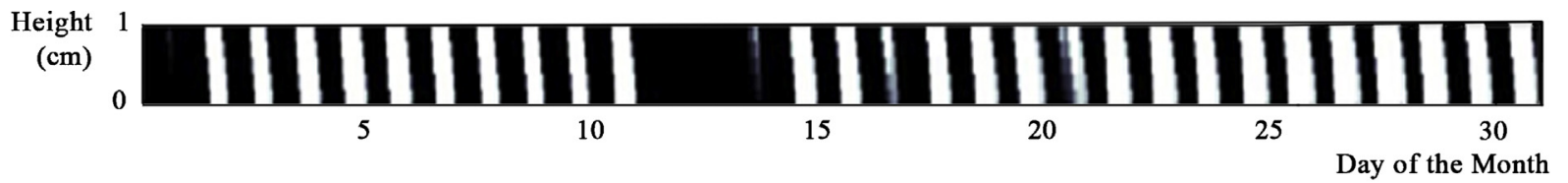

a) $1 \mathrm{~cm}$ PCM in May

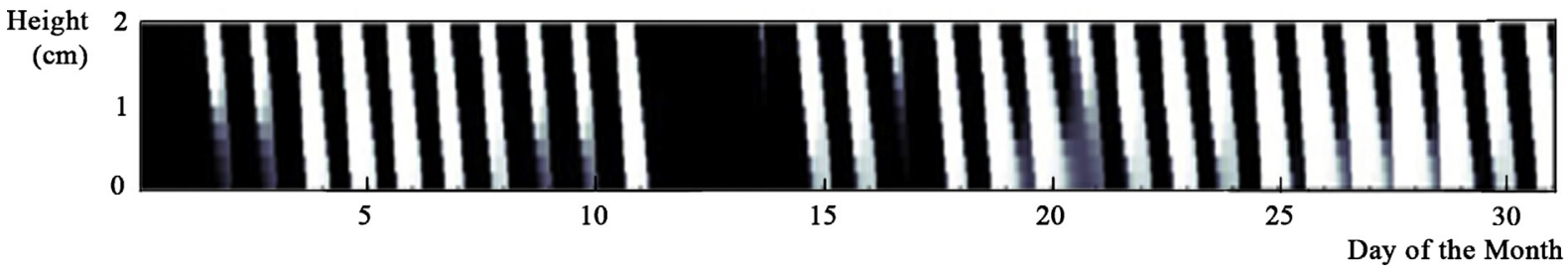

b) $2 \mathrm{~cm} \mathrm{PCM}$ in May

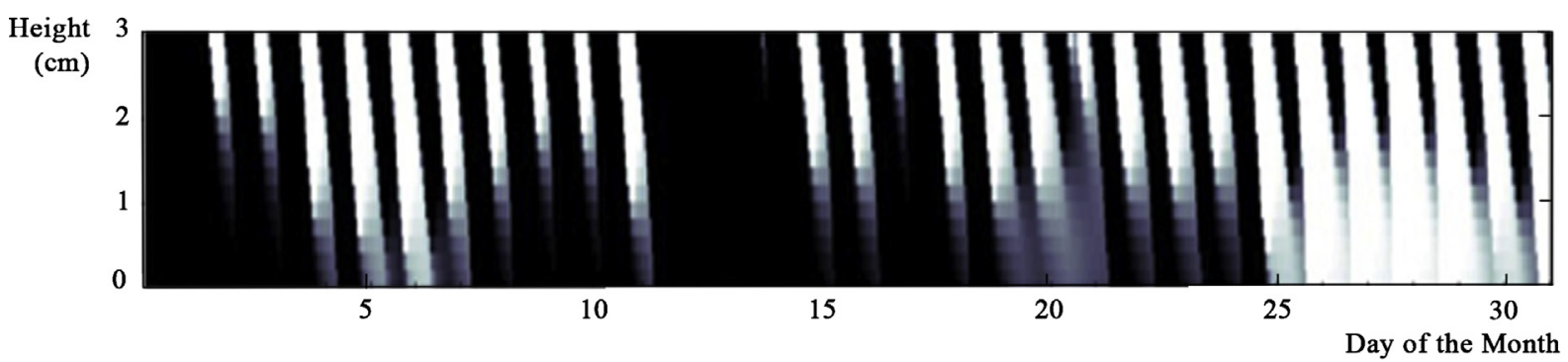

c) $3 \mathrm{~cm}$ PCM in May

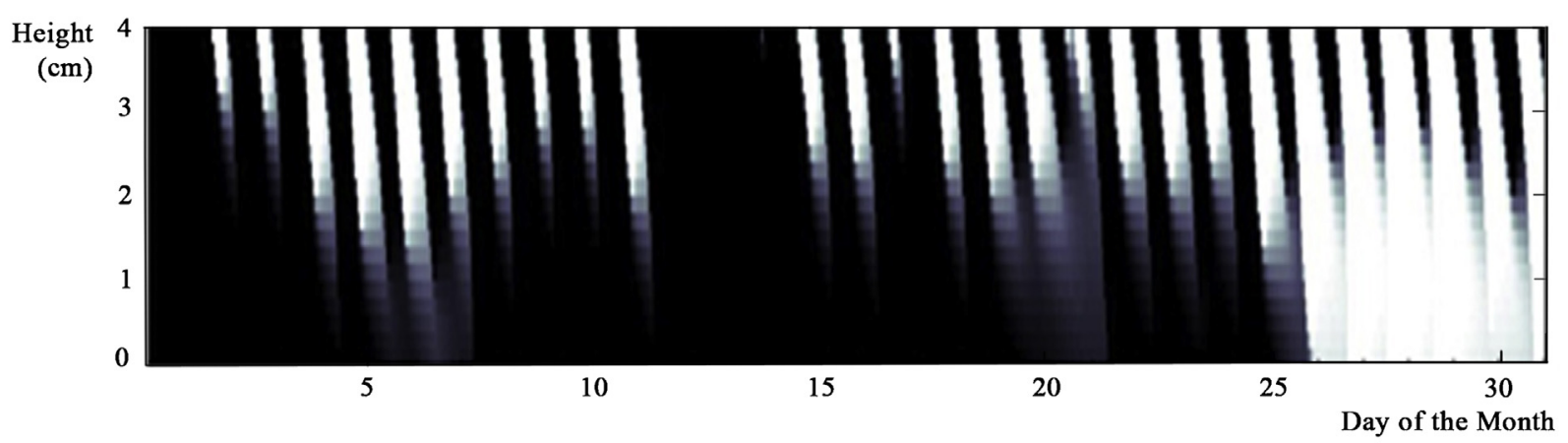

d) $4 \mathrm{~cm} \mathrm{PCM} \mathrm{in} \mathrm{May}$

Fig. 13. Solid-liquid states for varying PCM thicknesses in May (black denotes solid, white represents liquid, and the darkness of grey indicates the level of transition).

The $\alpha$ value used in the calculation of the surface temperature is taken from the measurement results of Prado and Ferreira [16].

$I, T_{\text {sky }}$ and $T_{\infty}$ are time-dependent variables due to the climatic conditions. $T_{\text {sky }}$ is calculated using Eq. (11), which depends on $T_{\infty}$ (ambient temperature) and $T_{\mathrm{dp}}$ (dew point temperature) [K] according to Davies [17]:

$T_{\text {sky }}=T_{\infty}\left(0.8+\frac{T_{\mathrm{dp}}-273}{250}\right)^{0.25}$

The climate data are entered into the simulation as timedependent user-defined functions. $h_{\mathrm{o}}$ and $h_{\mathrm{i}}$ (the thermal convection coefficient for outdoors and indoors) $\left[\mathrm{W} / \mathrm{m}^{2} \mathrm{~K}\right]$ values are constant in the simulation and are taken from the Turkish Standard TS-825, Thermal Insulation Standard in Buildings (2008) [21].

The simulation was performed to evaluate the impact of the roof on the cooling load; therefore, five months in which the cooling load is dominant, between May and September, are simulated. The initial temperature conditions of the roof were obtained by running the simulation for the last 3 days of April. Simulations were performed for the roof details containing PCM 1-, 2-, 3-, 4- and 5-cm thickness. The main outputs are the melting interface of the PCM and the heat flux at the indoor surface of the roof. The PCM interface graphs show the time and thickness when the PCM is active, while the heat flux calculations show the amount of energy entering the interior through the roof.

\subsection{The case of Istanbul}

The city of Istanbul is at $41^{\circ}$ latitude and $28.8^{\circ}$ longitude and is $37 \mathrm{~m}$ above sea level. Although the climate of Istanbul has the main characteristics of the Mediterranean climate, the influence of the Sea of Marmara and the Bosphorus impacts are considerable. In winter months, Istanbul is under the influence of the cold-dry air that comes from the Black Sea, the cold-rainy air that comes from the Balkans, and especially the warm and rainy air that comes from the Mediterranean. Both summer and winter are humid, while fall, winter and spring are rainy. The summer months are usually hot; however, the winter months are not too cold.

Simulations use the climate values from the Meteonorm Database [18], which are partially given in Figs. 10 and 11. The 


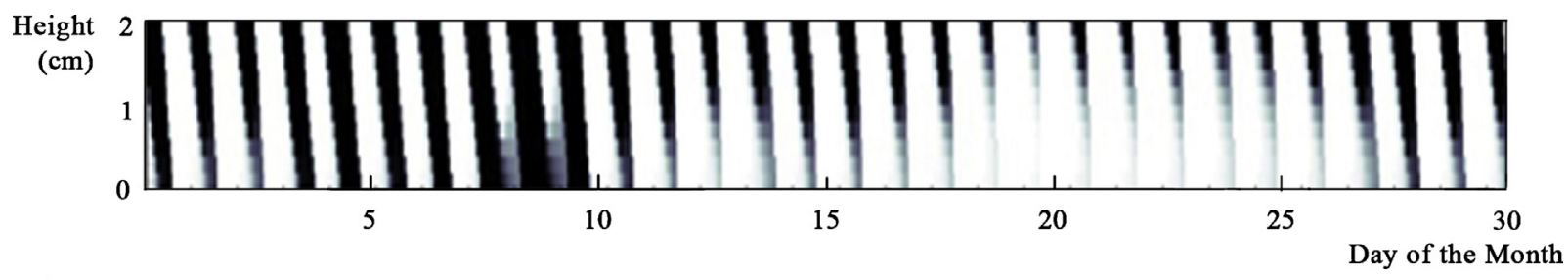

a) $2 \mathrm{~cm}$ PCM in June

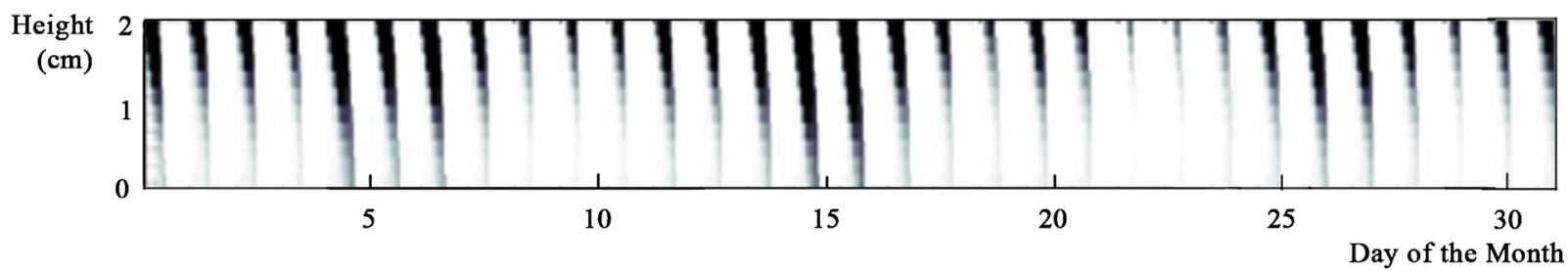

a) $2 \mathrm{~cm}$ PCM in July

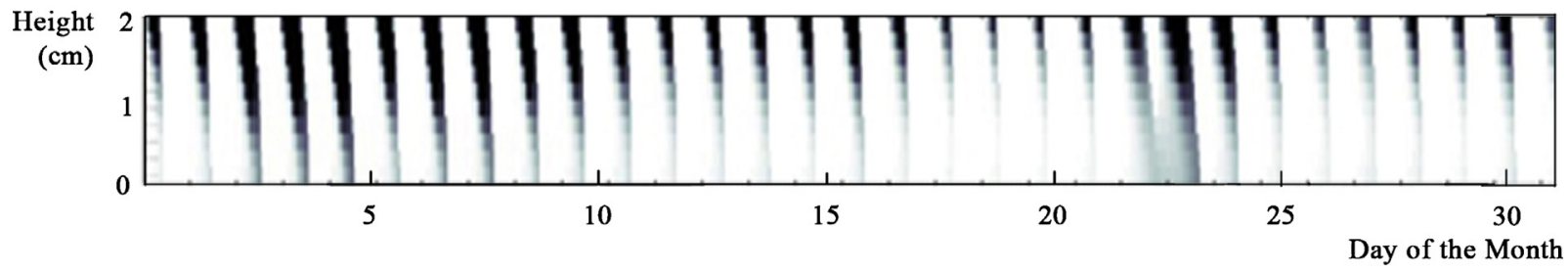

c) $2 \mathrm{~cm}$ PCM in August

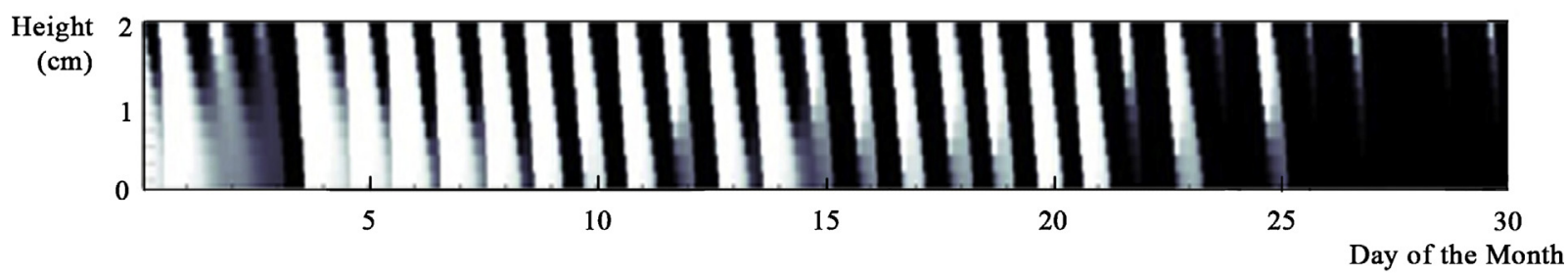

d) $2 \mathrm{~cm} \mathrm{PCM}$ in September

Fig. 14. Solid-liquid states for 2-cm PCM from June to September (black denotes solid, white represents liquid, and the darkness of grey indicates the level of transition).

simulation results for a flat roof containing PCM of $5 \mathrm{~cm}$ in height for 5 months in İstanbul are given in Fig. 12. The figure shows the times when PCM is solid (black), liquid (white), or in transition (grey) for the days of the simulated months. During May (Fig. 12a), there are days when the PCM does not work, completes a phase change cycle, or partially completes a cycle. The outdoor temperature increases in June (Fig. 12b), July (Fig. 12c) and August (Fig. 12d); thus, the PCM is usually in the liquid phase, and the benefits of PCM usually stem from the sensible heat storage. However, in September (Fig. 12e), while the PCM works less in the first 10 days of the month, it works efficiently during the second 10 days and remains mostly solid in the last days.

As observed from Fig. 12, the PCM of 5-cm thickness is not effective for summer conditions. Therefore, PCM thicknesses of 1, 2, 3 and $4 \mathrm{~cm}$ were also evaluated. Graphs of varying the PCM thickness for the month of May are shown in Fig. 13.

When the graphs for all five months are evaluated, the PCM of $2-\mathrm{cm}$ thickness shows the best performance among the five thicknesses. Fig. 14 shows the melting solidification cycles for the 2-cm-thick PCM from June to September.

\section{Results and discussion}

The main aim of this study is to provide a method that would evaluate the potential effects of PCM to improve the comfort conditions in buildings. The method incorporates experimental and numerical works. The experimental work with PCM is repeated; as a result, the temperature differences are $0.07 \%$ for $50{ }^{\circ} \mathrm{C}, 0.82 \%$ for $40{ }^{\circ} \mathrm{C}$, and $0.44 \%$ for $60^{\circ} \mathrm{C}$. In addition, the energy differences are $0.33 \%$ for $50{ }^{\circ} \mathrm{C}, 2.45 \%$ for $40^{\circ} \mathrm{C}$, and $4.38 \%$ for $60^{\circ} \mathrm{C}$.

During the experiment, graphs showing time-dependent temperature change in the surfaces and PCM melting photographs were obtained and used to comment on the behaviour of the PCM. The PCM is $4.4 \mathrm{~cm}$ thick as a solid and $5 \mathrm{~cm}$ thick as a liquid. Manufacturers reported that the PCM used in the experiments exhibits stable performance under repeated phase change. No degradation was observed in the PCM during the experiment. The melting interface showed continuity, in accordance with expectations. Instead of the entire surface of the PCM moving together uniformly, the phase change occurred primarily at the edges, and a slight bump was seen in the centre. 
After the experimental work, the thermal behaviour of the building element was solved numerically using ANSYS FLUENT software, which uses the finite volume method for calculations. In FLUENT, the defined geometry is divided into control volumes, and the equations representing each control volume are solved iteratively. Because the mesh size, time step, and convergence criteria affect the solution results, three alternatives were tested for each variable before determining their values in the simulation. The statistical analyses between the experimental and numerical studies of the model reveal a difference of $0.28 \%$ without PCM and $5.30 \%$ for the experiment with PCM for $72 \mathrm{~h}$.

As a result, the amount of PCM in the building element determined the thermal energy storage capacity. When all of the PCM changes phase, the storage capacity reaches its peak. During seasonal transition periods, solar energy can be stored actively, i.e., the latent heat effect is observed more frequently during the months of May and September. In May, the heat flux passing through the roof incorporating PCMs of $1-\mathrm{cm}, 2-\mathrm{cm}, 3-\mathrm{cm}, 4-\mathrm{cm}$, and $5-\mathrm{cm}$ thickness decreases $17.8 \%, 36.1 \%, 43.2 \%, 49.7 \%$, and $56.6 \%$, respectively; therefore, May is the month when most of the benefit is obtained. However, in September, another transition month, the heat flux passing through the roof incorporating PCMs of 1-cm, 2$\mathrm{cm}, 3-\mathrm{cm}, 4-\mathrm{cm}$, and $5-\mathrm{cm}$ thickness are reduced by $11.0 \%, 18.3 \%$, $16.6 \%, 13.5 \%$, and $10.8 \%$, respectively. While the reductions are more than those during the summer months, they are not as high as in May; thus, the latent heat effect is utilised less compared to May.

In summer conditions, after a few hot summer days, the latent heat stored in the liquid PCM cannot be given to the external environment; as a result, the solidification melting cycle does not activate. During the months of July and August, the decrease in the heat flux passing through the roof incorporating PCM of $1-\mathrm{cm}$, $2-\mathrm{cm}, 3-\mathrm{cm}, 4-\mathrm{cm}$, and $5-\mathrm{cm}$ thickness are very similar, approximately $2.1 \%, 4.1 \%, 6.0 \%, 7.8 \%$, and $9.6 \%$, respectively. Thus, most of the perceived improvement in the roof performance in July and August is due to the sensible heat capacity. The evaluation of other PCM is possible with the use of this methodology.

\section{Conclusion}

Due to various economic, environmental and social imperatives of the last decades, more efficient use of fossil sources in energy consumption and increasing the use of renewable energy sources in total energy consumption are required. Therefore, sustainable design and implementation of buildings, where a significant portion of the total energy consumption takes place, is a worldwide trend. In this context, the most important strategies that can be implemented to ensure the sustainability of buildings include consuming energy in a manner that is as efficient as possible, producing the required energy in the building using renewable energy sources, and utilising local building materials.

This study contributes to the knowledge of the integration of PCMs as latent heat storage materials into building elements.

The method introduced in this study generates a flexible model that can be used to inspect the effect of many variables in the building envelope under different climatic conditions. Some of these possible future studies include investigation of changing the amounts of PCM, the PCM types, several details of a building element, the distinctive properties of surface materials, the orientation to the sun, the types of shadowing, indoor temperatures, climatic characteristics and night ventilation.

The numerical results show that the micro-climatic conditions of the building site should also be carefully analysed before choosing the appropriate PCM and building technology. The 5-cmthick PCM stays liquid in Istanbul during the months of June, July and August. Therefore, the latent heat effect of the system cannot be utilised as desired, and the resulting effect is caused more by sensible heat. Thus, RT27 is more successful as a PCM during the transition months. In addition, in the winter, the outdoor temperatures are typically under $25^{\circ} \mathrm{C}$, which ensures that the PCM would be solid most of the time. The results suggest that in a climate with four seasons, any PCM cannot be successful in all four seasons. As a result, the continuation of this work can consider the potential of using two or more PCMs for different seasonal conditions as well as PCM geometries other than the flat body geometry considered here.

\section{Acknowledgements}

This study is funded by the Dokuz Eylul University research project 2010.KB.FEN.011. The authors thank the Scientific Research Projects Coordination Unit of Dokuz Eylul University for their support.

\section{Appendix A. Supplementary data}

Supplementary data associated with this article can be found, in the online version, at http://dx.doi.org/10.1016/j.enbuild.2015.04. 039

\section{References}

[1] A. Abhat, Low temperature latent heat thermal energy storage: heat storage materials, Solar Energy 30 (4) (1983) 313-332.

[2] M.M. Farid, A.M. Khudhair, S.A. Razack, S. Al-Hallaj, A review on phase change energy storage: materials and applications, Energy Convers. Manag. 45 (2004) 1597-2161, http://dx.doi.org/10.1016/j.enconman.2003.09.015

[3] A.Z. Waqas, Z. Ud Din, Phase change material (PCM) storage for free cooling of buildings-a review, Renew. Sustain. Energy Rev. 18 (February) (2013) 607-625, http://dx.doi.org/10.1016/j.rser.2012.10.034

[4] R. Baetens, B.P. Jelle, A. Gustavsen, Phase change materials for building applications: a state-of-the-art review, Energy Build. 42 (9 (September)) (2010) 1361-1368, http://dx.doi.org/10.1016/j.enbuild.2010.03.026

[5] N. Soares, J.J. Costa, A.R. Gaspar, P. Santos, Review of passive PCM latent heat thermal energy storage systems towards buildings' energy efficiency, Energy Build. 59 (April) (2013) 10-82, http://dx.doi.org/10.1016/j.enbuild.2012.12. 042

[6] M. Pomianowski, P. Heiselberg, Y. Zhang, Review of thermal energy storage technologies based on PCM application in buildings, Energy Build. 67 (December) (2013) 56-69, http://dx.doi.org/10.1016/j.enbuild.2013.08. 006

[7] H.-M. Chou, C.-R. Chen, V.-L. Nguyen, A new design of metal-sheet cool roof using PCM, Energy Build. 57 (February) (2013) 42-50, http://dx.doi.org/10. 1016/j.enbuild.2012.10.030

[8] H.J. Alqallaf, E.M. Alawadhi, Concrete roof with cylindrical holes containing PCM to reduce the heat gain, Energy Build. 61 (June) (2013) 73-80, http://dx. doi.org/10.1016/j.enbuild.2013.01.041

[9] M. Santamouris, A. Synnefa, T. Karlessi, Using advanced cool materials in the urban built environment to mitigate heat islands and improve thermal comfort conditions, Solar Energy 85 (12 (December)) (2011) 3085-3102, http://dx.doi. org/10.1016/j.solener.2010.12.023

[10] Y. Dutil, D.R. Rousse, N.B. Salah, S. Lassue, L. Zalewski, A review on phase-change materials: mathematical modeling and simulations, Renew. Sustain. Energy Rev. 15 (1 (January)) (2011) 112-130, http://dx.doi.org/10.1016/j.rser.2010.06. 011

[11] J.P. Holman, Experimental Methods for Engineers, Eighth Edition, McGraw-Hill, New York, 2011.

[12] M.A. Ezan, A. Erek, I. Dincer, Energy and exergy analyses of an ice-on-coil thermal energy storage system, Energy 36 (11 (November)) (2011) 6375-6386, http://dx.doi.org/10.1016/j.energy.2011.09.036

[13] ANSYS Inc. (2009). ANSYS FLUENT 12.0 Theory Guide.

[14] A.A. Al-abidi, S.B. Mat, K. Sopian, M.Y. Sulaiman, A.T. Mohammed, CFD applications for latent thermal energy storage: a review, Renew. Sustain. Energy Rev. 20 (April) (2013) 353-363, http://dx.doi.org/10.1016/j.rser.2012.11. 079

[15] F. Sheth Karathia, Analysis of thermal properties of phase change materials (PCM) using differential scanning calorimeter (DSC), Universitat de Lleida Escola Politècnica Superior Màster en Ciències Aplicades a l'Enginyeri., Lleida, 2011 (Treball de final de master). 
[16] R.T.A. Prado, F.L. Ferreira, Measurement of albedo and analysis of its influence the surface temperature of building roof materials, Energy Build. 37 (4 (April)) (2005) 295-300, http://dx.doi.org/10.1016/j.enbuild.2004.03.009

[17] M.G. Davies, Building Heat Transfer, John Wiley \& Sons, Wiltshire, 2004.

[18] Meteonorm Database (2012). Climate data for İstanbul.

[19] Rubitherm Gmbh (2009). Technical Data Sheet for Rubitherm ${ }^{\circledR}$ RT27.

[20] A. Tokuc, T. Başaran, S.C. Yesügey. Experimental data showing the thermal behavior of a flat roof with phase change material. Data in Brief "submitted".
[21] Turkish Standards Institution (2008). TS 825 Thermal insulation requirements for buildings.

[22] A. Tokuç, Faz değișim malzemelerinin ısıl enerji depolama amacıyla yapı elemanı üretiminde kullanılması (Use of phase change materials in building elements for thermal energy storage), Dokuz Eylül University Institute of Natural Sciences, İzmir, 2013 (Unpublished PhD Thesis). 